\title{
Magnetic Composite Sorbents for Trapping Heavy Metals from Liquid Waste and Their Immobilization in a Mineral-Like Matrix
}

\author{
Yana Yu. Chernykh, \\ Tatiana A. Vereshchagina, Elena V. Mazurova, \\ Vladimir A. Parfenov, Leonid A. Solovyev, \\ Sergey N. Vereshchagin and Olga M. Sharonova* \\ Institute of Chemistry and Chemical Technology SB RAS, \\ FRC "Krasnoyarsk Science Center SB RAS" \\ 50/24 Akademgorodok, Krasnoyarsk, 660036, Russia
}

Received 27.02.2019, received in revised form 28.01.2019, accepted 24.08.2019

\begin{abstract}
Magnetic sorbents were prepared by addition of ferrospheres to zirconia-silica gel followed by thermal treatment at $500^{\circ} \mathrm{C}$. The ferrosphere narrow fraction $\mathrm{E}-0.063+0.050 \mathrm{~mm}$ from fly ash resulted from combustion of Ekibastuz coal was used as a magnetic component. The surface of magnetic composites was additionally functionalized by grafting of - POONa and $-\mathrm{NH}_{2}$ groups. Under equilibrium conditions sorption capacities of the sorbents with respect to $\mathrm{Ce}^{3+}$ used as a $U^{4+} / \mathrm{Th}^{4+}$ simulator and $\mathrm{Pb}^{2+}$ were measured by means of determination of sorption isotherms which were fitted by the Langmuir model. It was established that extraction of $\mathrm{Ce}^{3+}$ and $\mathrm{Pb}^{2+}$ from aqueous solutions is characterized by distribution coefficients of $10^{4}-10^{6} \mathrm{ml} / \mathrm{g}$. Temperature conditions for solid-phase crystallization of the sorbents resulting in polyphase systems with the content of zircon phase of $50 \mathrm{wt}$. \% were found.
\end{abstract}

Keywords: ferrospheres, magnetic sorbents, zirconosilicates, heavy metals, zircon.

Citation: Chernykh Ya.Yu., Vereshchagina T.A., Mazurova E.V., Parfenov V.A., Solovyev L.A., Vereshchagin S.N., Sharonova O.M. Magnetic composite sorbents for trapping heavy metals from liquid waste and their immobilization in a mineral-like matrix, J. Sib. Fed. Univ. Chem., 2019, 12(3), 445-457. DOI: 10.17516/1998-2836-0141.

(C) Siberian Federal University. All rights reserved

* Corresponding author E-mail address: yaninachernyh@yandex.ru, tatiana@icct.ru 


\title{
Магнитные композитные сорбенты
}

\section{для извлечения тяжелых металлов из жидких отходов \\ и их иммобилизации в минералоподобной матрице}

\author{
Я.Ю. Черных, Т.А. Верещагина, \\ Е.В. Мазурова, В.А. Парфенов, \\ Л.А. Соловьев, С.Н. Верещагин, О.М. Шаронова \\ Институт химии и химической технологии СО РАН \\ ФИЦ «Красноярский научный иентр СО РАН» \\ Россия, 660036, Красноярск, Академгородок, 50/24
}

Магнитные сорбенты получали смешиванием ферросфер с иирконосиликагелем с последующей термической обработкой композиций при $500{ }^{\circ} \mathrm{C}$. В качестве магнитного компонента использовали узкую фракиию ферросфер E-0,063+0,050 мм, выделенную из летучей золь от сжигания экибастузского угля. Дополнительно поверхность полученных магнитных композиций активировали путем нанесения функциональных групn $-\mathrm{POONa} u-\mathrm{NH}_{2}$. B равновесных условиях измерены сорбционные емкости сорбентов в отношении катионов $\mathrm{Ce}^{3+}$ как имитатора $\mathrm{U}^{4+} / \mathrm{Th}^{4+}$ и $\mathrm{Pb}^{2+}$ путем построения изотерм сорбичи, которые были аппроксимированы моделью Ленгмюра. Установлено, что извлечение катионов $\mathrm{Ce}^{3+} u \mathrm{~Pb}^{2+}$ из водных сред протекает с коэффициентами распределения $10^{4}-10^{6}$ мл/2. Определены условия твердофазной кристаллизаџии сорбентов с формированием полифазной системы, в которой содержание фазы ииркона достигает 50 мас. \%.

Ключевые слова: ферросферы, магнитные сорбенты, иирконосиликаты, тяжелые металлы, циркон.

\section{Введение}

Экологическая безопасность освоения ресурсов недр не может быть достигнута без решения проблемы нейтрализации вредного воздействия жидких отходов горно-обогатительных и химико-металлургических производств на природную среду. Повышенную опасность для биосферы представляют жидкие токсичные отходы от переработки золотосодержащих и редкометалльно-редкоземельных руд, которые содержат природные радионуклиды $\left({ }^{232} \mathrm{Th}\right.$, ${ }^{238} \mathrm{U},{ }^{226} \mathrm{Ra}$ ) в сочетании с тяжелыми металлами ( $\left.\mathrm{Pb}, \mathrm{Hg}, \mathrm{Cd}, \mathrm{Cr}(\mathrm{VI}), \mathrm{Be}\right)$, относящиеся к приоритетным токсикантам и требующие эффективной долговременной изоляции от биосферы $[1,2]$.

За счет сходства вещественного состава токсичных слаборадиоактивных отходов цветной металлургии с высокоактивными отходами (BAO) атомной отрасли их можно рассматривать в одной категории отходов, обращение с которыми может быть реализовано в рамках подхода, принятого в отношении ВАО, т.е. путем их включения в устойчивые минералоподобные матрицы с последующим захоронением в геологических формациях [3]. В настоящее время 
надежным способом иммобилизации тяжелых металлов и других нерадиоактивных опасных отходов является их включение в стекло или стеклокерамические матрицы [4].

В качестве устойчивых минералоподобных матриц ВАО рассматриваются Zr-содержащие фазы, в частности фаза $\mathrm{ZrSiO}_{4}$, фиксирующая отходы сложного состава и представляющая собой химический и структурный аналог минерала циркона $[5,6]$. Циркон является чрезвычайно устойчивым минералом, который за счет высоких концентраций U в своей структуре (до 20000 $\mathrm{ppm)} \mathrm{используется} \mathrm{для} \mathrm{датирования} \mathrm{возраста} \mathrm{по} \mathrm{соотношению} \mathrm{U} / \mathrm{Pb}[5,7]$. Разработка технологий получения таких матриц для иммобилизации радионуклидов и тяжелых металлов - важная научная и практическая задача, которая может быть решена в рамках сорбционной схемы перевода катионов металлов из растворов в структуру твердой матрицы путем высокотемпературного фазового превращения сорбированных форм металлов $[8,9]$.

Для реализации сорбционной схемы изоляции $\mathrm{U}, \mathrm{Th}$ и тяжелых металлов в фазе циркона представляют интерес сорбционно-активные материалы на основе мезопористых силикатов циркония $[10,11]$. При этом актуальна задача получения гранулированной формы цирконосиликатного сорбента, обеспечивающей извлечение катионов металлов из водных сред с коэффициентами распределения $10^{4}-10^{6}$ мл/г.

Большим потенциалом использования в качестве носителя сорбционно-активных соединений обладают стеклокристаллические железоалюмосиликатные микросферы, образующиеся при высокотемпературном сжигании пылевидного угля на ТЭС $[12,13]$. Одной из разновидностей микросфер в летучих золах выступают ферросферы с содержанием железа 30-90 мас. \% $\mathrm{Fe}_{2} \mathrm{O}_{3}$, в структуру которых входят ферромагнитные фазы ферритовых шпинелей [14]. Преимуществом использования ферросфер в процессах обращения с жидкими токсичными отходами является возможность создания магнитоуправляемых сорбционных технологий, основанных на магнитных свойствах ферросфер. Наличие в составе различных фракций ферросфер аморфной алюмосиликатной составляющей с содержанием от 15 до 62 мас. \% дает возможность синтеза на поверхности ферросфер цеолитных фаз [15], обладающих ионообменными и сорбционными свойствами $[16,17]$. Другим вариантом получения инженерной формы магнитного сорбента может быть агломерация ферросфер с использованием цирконосиликатного связующего, выполняющего также функцию сорбционно-активного компонента и прекурсора фазы циркона. Микросферические сорбенты такого типа были получены в работах $[18,19]$ путем консолидации алюмосиликатных микросфер с силикатным связующим.

Целью данной работы стало получение гранулированной формы цирконосиликатного сорбента с магнитными свойствами на основе композиций ферросфер и мезопористых цирконосиликатов, изучение их сорбционных свойств (емкость, коэффициент распределения) в отношении катионов $\mathrm{Ce}^{3+}$ (как имитатора урана и тория) и $\mathrm{Pb}^{2+}$, а также фазового состава продуктов высокотемпературной твердофазной кристаллизации $\mathrm{Ce}^{3+} / \mathrm{Pb}^{2+}$ обменных форм сорбентов.

\section{Экспериментальная часть}

Реактивы и материаль: тетраэтоксисилан (ТЭОС) $\mathrm{Si}\left(\mathrm{C}_{2} \mathrm{H}_{5} \mathrm{O}\right)_{4}$ о.с.ч., ТУ 2637-059-4449317904; хлорид цирконила $\mathrm{ZrOCl}_{2} \cdot 8 \mathrm{H}_{2} \mathrm{O}$ ч., ТУ 6-09-3677-74; этанол $\left(\mathrm{C}_{2} \mathrm{H}_{5} \mathrm{OH}\right), 96$ мас. \%; Na-соль бис-(2,4,4-триметилпентил)фосфиновой кислоты ( $\left.\mathrm{R}_{2} \mathrm{POONa}\right)$, получена взаимодействием $\mathrm{NaOH}$ с бис-(2,4,4-триметилпентил)фосфиновой кислотой (CYANEX 272, CYTEC Canada);

$$
-447-
$$




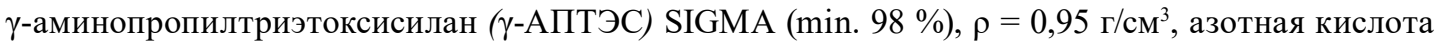
$\mathrm{HNO}_{3}$ х.ч.; соляная кислота $\mathrm{HCl}$ х.ч.

В качестве магнитного компонента сорбента использовали узкую фракцию ферросфер Е $-0,063+0,050$ мм, выделенную из летучей золы от сжигания экибастузского угля (рис. 1) $[14,20]$. Химический и фазовый состав исходной фракции ферросфер, величины насыпной плотности,

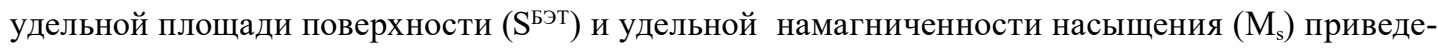
ны в табл. 1. С целью увеличения концентрации -ОН на поверхности ферросфер микросферы предварительно активировали обработкой паром в гидротермальных условиях при температуре $180{ }^{\circ} \mathrm{C}$ в течение 5 ч согласно [21].

\section{Синтез композитного сорбента}

Получение композиций ферросфер с цирконосиликатным связующим осуществляли в условиях синтеза цирконосиликагеля в присутствии ферросфер в кислой водно-спиртовой среде, содержащей в качестве прекурсоров тетраэтоксисилан $\mathrm{Si}\left(\mathrm{C}_{2} \mathrm{H}_{5} \mathrm{O}\right)_{4}(\mathrm{TЭOC})$ и хлорид цирконила $\mathrm{ZrOCl}_{2}$ при мольном соотношении $\mathrm{Zr} /(\mathrm{Zr}+\mathrm{Si})$ 0,33; 0,$4 ; 0,5$ и 0,6. Образование цирконосиликагеля осуществлялось в результате последовательных стадий формирования коллоидного золя с ферросферами при $65^{\circ} \mathrm{C}$, нейтрализации золя раствором аммиака с образованием геля и его ступенчатой термической обработки согласно методике [22]. Из полученного порошка отделяли магнитную часть постоянным магнитом.

Дополнительно проводили функционализацию поверхности композиции $0.5 \mathrm{Zr}-0.5 \mathrm{Si}$ Fer группами -POONa путем нанесения бис-(2,4,4-триметилпентил)-фосфиновой кислоты

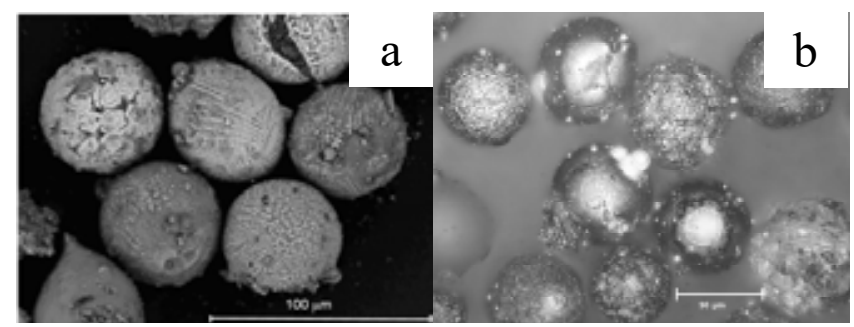

Рис. 1. Снимки исходной фракции ферросфер по данным электронной (a) и оптической (b) микроскопии Fig. 1. SEM (a) and optic microscopy (b) images of the initial ferrosphere fraction

Таблица 1. Макрокомпонентный, фазовый состав и физические характеристики исходной фракции ферросфер

Table 1. Macrocomponent and phase composition, physical characteristics of the initial ferrosphere fraction

\begin{tabular}{|c|c|c|c|c|c|c|c|c|c|c|}
\hline \multicolumn{8}{|c|}{ Содержание, мас. \% } & \multirow{3}{*}{$\begin{array}{c}\sum_{0}^{n} \\
0 \\
\vdots \\
\tilde{y} \\
0 \\
0\end{array}$} & \multirow{3}{*}{ 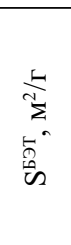 } & \multirow{3}{*}{$\begin{array}{l}\frac{5}{j} \\
\sum_{j}^{5} \\
\sum^{\hat{n}}\end{array}$} \\
\hline \multicolumn{3}{|c|}{ Макроэлементы } & \multicolumn{4}{|c|}{ Кристаллические фазы } & \multirow{2}{*}{ 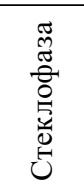 } & & & \\
\hline $\mathrm{SiO}_{2}$ & $\mathrm{Al}_{2} \mathrm{O}_{3}$ & $\mathrm{Fe}_{2} \mathrm{O}_{3}$ & 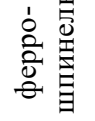 & гематит & кварц & муллит & & & & \\
\hline 26,5 & 9,4 & 59,8 & 48,8 & 2,9 & 3,1 & 3,5 & 41,2 & 1,4 & 1,3 & 35,8 \\
\hline
\end{tabular}


( $\mathrm{R}_{2} \mathrm{POONa}$ [23] методом пропитки по влагоемкости раствором указанного соединения в этаноле с последующей сушкой при $60^{\circ} \mathrm{C}$ (образец $\mathrm{R}_{2} \mathrm{POONa} / 0.5 \mathrm{Zr}-0.5 \mathrm{Si}-\mathrm{Fer}$ ). Содержание нанесенного соединения определяли по приращению массы образца, которое составило 10,8 мас. \%.

Аминирование поверхности проводили согласно методике [24]. Навеску заливали 5\%ным водным раствором $\gamma$-аминопропилтриэтоксисилана ( $\gamma$-АПТЭС), выдерживали при $75{ }^{\circ} \mathrm{C}$ в течение 30 мин, а затем промывали 10-кратным объемом воды, после чего высушивали при $120{ }^{\circ} \mathrm{C}$ (образец $\left.\mathrm{RNH}_{2} / 0.5 \mathrm{Zr}-0.5 \mathrm{Si}-\mathrm{Fer}\right)$.

\section{Физико-химические методы исследования}

Определение удельной поверхности и размера пор композиций проводили исходя из объема азота, адсорбированного при 77 К, с использованием анализатора ASAP 2020 MP-C (Micromeritics, США).

Температурный режим кристаллизации полученных сорбентов выбирали на основе данных синхронного термического анализа (Netzsch STA Jupiter 449C/AELOSQMS403C, Германия). Эксперименты проводили в потоке смеси $20 \% \mathrm{O}_{2}-\mathrm{Ar}$ в платиновых тиглях с перфорированными крышками, масса навески 4 мг. Температурная программа включала температурную стабилизацию при $40{ }^{\circ} \mathrm{C}$ в течение 30 мин, за которой следовал нагрев до $1200{ }^{\circ} \mathrm{C}$ со скоростью $10{ }^{\circ} \mathrm{C} \cdot$ мин $^{-1}$. Качественный состав отходящих газов оценивали по изменению интенсивности ионов с m/z $18\left(\mathrm{H}_{2} \mathrm{O}\right), 18\left(\mathrm{O}_{2}\right)$ и $44\left(\mathrm{CO}_{2}\right)$.

Структуру и фазовый состав определяли методом порошкового рентгенофазового анализа с использованием подхода Ритвельда [25] и метода минимизации производной разности [26]. РФА-спектры записывали на дифрактометре PANalytical X'Pert PRO MPD (Нидерланды) с твердотельным детектором PIXel и вторичным графитовым монохроматором для $\mathrm{Cu}_{\alpha}$ излучения.

Исследование морфологии образцов осуществляли методом сканирующей электронной микроскопии (СЭМ, РЭМ) на микроскопе ТМ-3000 (Hitachi, Япония).

Содержание аминогрупп $-\mathrm{NH}_{2}$ на поверхности определяли титрованием соляной кислотой [24]. Для этого навеску 300-400 мг заливали $15-25$ мл 0,01M HCl и выдерживали 20-25 мин. Затем раствор отфильтровывали, отбирали 3 пробы по 5 мл и оттитровывали их $0,01 \mathrm{M} \mathrm{NaOH} \mathrm{c}$ индикатором метилрот. Количество аминогрупп определяли по формуле (1):

$$
\mathrm{n}_{\mathrm{NH} 2}=\frac{\mathrm{V}\left(\mathrm{C}_{0}-\mathrm{Cp}\right)}{\mathrm{m}}
$$

где $n_{N H 2}-$ количество групп - $\mathrm{NH}_{2}$, приходящееся на 1 г носителя, м-экв/г; $\mathrm{V}$ - объем исходного раствора $\mathrm{HCl}$, мл; $\mathrm{C}_{0}$ и $\mathrm{C}_{\mathrm{p}}\left(\mathrm{C}_{\mathrm{e}}\right)$ - исходная и равновесная концентрации $\mathrm{HCl}$, мл, соответственно; $m$ - навеска аминированного образца, г.

Сорбцию катионов церия и свинца проводили из водных растворов их нитратов при комнатной температуре в статических условиях методом переменных концентраций. Навеску сорбента $(0,0500 \pm 0,0005$ г) контактировали с раствором нитрата металла известной концентрации в течение 24 ч при комнатной температуре. По окончании сорбции твердую фазу отделяли от раствора постоянным магнитом, а сам раствор дополнительно фильтровали на бумажном фильтре “белая лента”. В исходном растворе и фильтрате методом масс-спектрометрии с индуктивно связанной плазмой (ICP-MS7500a, Agilent, США) измеряли исходную и равновесную

$$
-449-
$$


концентрации $\mathrm{Ce}^{3+}$ и $\mathrm{Pb}^{2+}$. Равновесную сорбционную емкость $\left(\mathrm{A}_{\mathrm{p}}\left(\mathrm{A}_{\mathrm{e}}\right)\right.$, мг/г) рассчитывали по формуле (2):

$$
\mathrm{Ap}=\frac{\left(\mathrm{C}_{0}-\mathrm{C}_{\mathrm{p}}\right) \cdot \mathrm{V}}{\mathrm{m}}
$$

где $\mathrm{C}_{0}$ - исходная концентрация катиона металла, мг/л; $\mathrm{C}_{\mathrm{p}}\left(\mathrm{C}_{\mathrm{e}}\right)$ - равновесная концентрация катиона металла в фильтрате, мг/л; V - объем исходного раствора, л; $\mathrm{m}$ - навеска сорбента, г.

Результаты представляли в виде зависимости $\mathrm{A}_{\mathrm{p}}\left(\mathrm{A}_{\mathrm{e}}\right)=\mathrm{f}\left(\mathrm{C}_{\mathrm{p}}\left(\mathrm{C}_{\mathrm{e}}\right)\right)$ и определяли соответствие полученной зависимости модели Ленгмюра (3):

$$
\mathrm{Ap}=\mathrm{a}_{\mathrm{m}} \frac{\mathrm{bCp}}{1+\mathrm{bCp}}
$$

где $\mathrm{a}_{\mathrm{m}}$ - емкость при насыщении, мг/г; $\mathrm{C}_{\mathrm{p}}\left(\mathrm{C}_{\mathrm{e}}\right)$ - равновесная концентрация иона металла, мг/л; $\mathrm{b}$ - коэффициент, л/мг.

В случае соответствия экспериментальных данных модели Ленгмюра определяли параметры $\mathrm{a}_{\mathrm{m}}$ и $\mathrm{b}$ уравнения (3) и рассчитывали коэффициент распределения $\left(\mathrm{K}_{\mathrm{D}}=\mathrm{A}_{\mathrm{p}} / \mathrm{C}_{\mathrm{p}}\right.$, мл/Г) для линейной части изотермы сорбции при $\mathrm{C}_{\mathrm{p}}<1$ мг/л.

Твердофазную кристаллизацию композиций проводили в электропечи ВТП-12/15 (Филиал АО “ВНИИЭТО”, Россия) в воздушной атмосфере при температуре $1200{ }^{\circ} \mathrm{C}$ в течение 1 ч при скорости нагрева $10{ }^{\circ} \mathrm{C} \cdot \mathrm{мин}^{-1}$.

\section{Результаты и обсуждение}

По данным РЭМ, продуктами синтеза являются гранулы агломератов ферросфер с цирконосиликатным связующим размером в среднем 0,2-0,3 мм, находящихся в смеси с отдельными глобулами ферросфер и частицами цирконосиликата. При этом доля гранулированного композитного материала в продуктах является наиболее высокой в реакционной смеси при соотношении $\mathrm{Zr} /(\mathrm{Zr}+\mathrm{Si})=0,5$ (рис. 2). Остальные продукты характеризуются значительным содержанием неагломерированных микросфер и дисперсного цирконосиликатного материала. Общее содержание цирконосиликата в композициях составило около 30 мас. \% (табл. 2).

По данным метода низкотемпературной адсорбции азота, удельная поверхность композиций с уменьшением отношения $\mathrm{Zr} /(\mathrm{Zr}+\mathrm{Si})$ увеличивается с 68 до 82 м²/г, при этом диаметр и об-
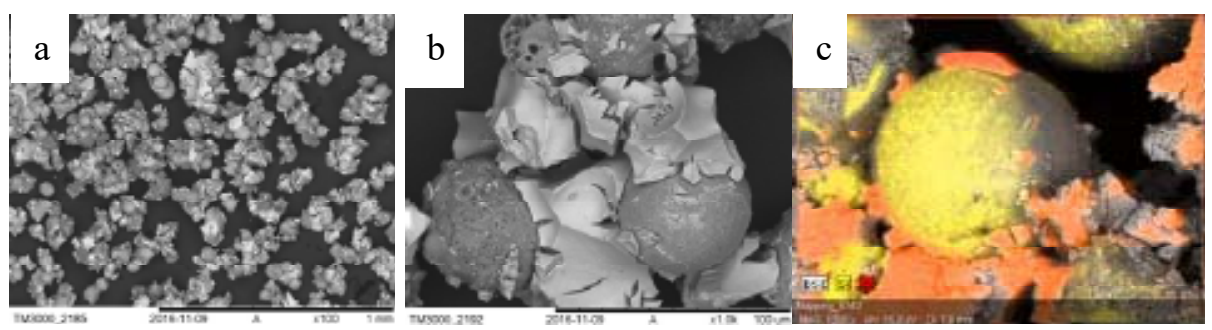

Рис. 2. РЭМ-снимки гранул композиции ферросфер с цирконосиликагелем (a-b); карта распределения $\mathrm{Zr}$ и $\mathrm{Si}$ по локальным участкам поверхности гранулы (c)

Fig. 2. SEM images of granules of a ferrosphere-zirconia-silica gel composite (a-b); $\mathrm{Zr}$ and Si distribution map over local sites of a granule surface (c) 
Таблица 2. Характеристики пористой структуры магнитных композиций

Table 2. Characteristics of porosity of magnetic composites

\begin{tabular}{|l|c|c|c|c|}
\hline \multicolumn{1}{|c|}{ Образец } & $\begin{array}{c}\text { Содержание } \\
\text { цирконосиликата, } \\
\text { мас. \% }\end{array}$ & $\mathrm{S}^{\text {Бэт }, \mathrm{m}^{2} / \Gamma}$ & Диаметр пор,$\AA$ & $\begin{array}{c}\text { Объем пор, } \\
\text { см}^{3} / \Gamma\end{array}$ \\
\hline $0.6 \mathrm{Zr}-0.4 \mathrm{Si}-\mathrm{Fer}$ & 31 & 68 & 48 & 0,070 \\
$0.5 \mathrm{Zr}-0.5 \mathrm{Si}-\mathrm{Fer}$ & 29 & 74 & 42 & 0,069 \\
$0.4 \mathrm{Zr}-0.6 \mathrm{Si}-\mathrm{Fer}$ & 28 & 80 & 38 & 0,068 \\
$0.33 \mathrm{Zr}-0.67 \mathrm{Si}-\mathrm{Fer}$ & 27 & 82 & $<20$ & 0,046 \\
\hline
\end{tabular}

*Рассчитан на основе адсорбционной ветви изотермы.

щий объем пор уменьшается (табл. 2). Образцы с соотношением $\mathrm{Zr} /(\mathrm{Zr}+\mathrm{Si})$ в интервале $0,6-0,4$ являются типичными мезопористыми материалами с размером пор 38-48 А⿱, в то время как в структуре композиции $0.33 \mathrm{Zr}-0.67 \mathrm{Si}-\mathrm{Fer}$ с минимальным содержанием циркония преобладают микропоры.

Для изучения влияния содержания $\mathrm{Zr}$ на эффективность сорбции в отношении катионов $\mathrm{Ce}^{3+}$ были выбраны два граничных образца - 0.6Zr-0.4Si-Fer и $0.33 \mathrm{Zr}-0.67 \mathrm{Si}$-Fer, которые отличаются как по соотношению $\mathrm{Zr} / \mathrm{Si}$, так и по типу пористой структуры (табл. 2). Обнаружено, что величина равновесной сорбционной емкости магнитных композиций в отношении Се $\mathrm{e}^{3+}$ обратно пропорциональна содержанию в них Zr. Так, в интервале концентраций $\mathrm{Ce}^{3+} 10-150$ мг/л величина равновесной сорбционной емкости образцов $0.6 \mathrm{Zr}-0.4 \mathrm{Si}-\mathrm{Fer}$ и $0.33 \mathrm{Zr}-0.67 \mathrm{Si}-\mathrm{Fer}$ изменяется в диапазонах 4-16 мг/г и 7-27 мг/г соответственно (рис. $3 a$ ).

Форма изотерм сорбции катионов $\mathrm{Ce}^{3+}$ характеризуется двумя максимумами, что может быть связано с наличием сорбционных центров двух типов [22], взаимодействие с которыми протекает по разным механизмам. В свою очередь, повышенная емкость композиции $0.33 \mathrm{Zr}-$
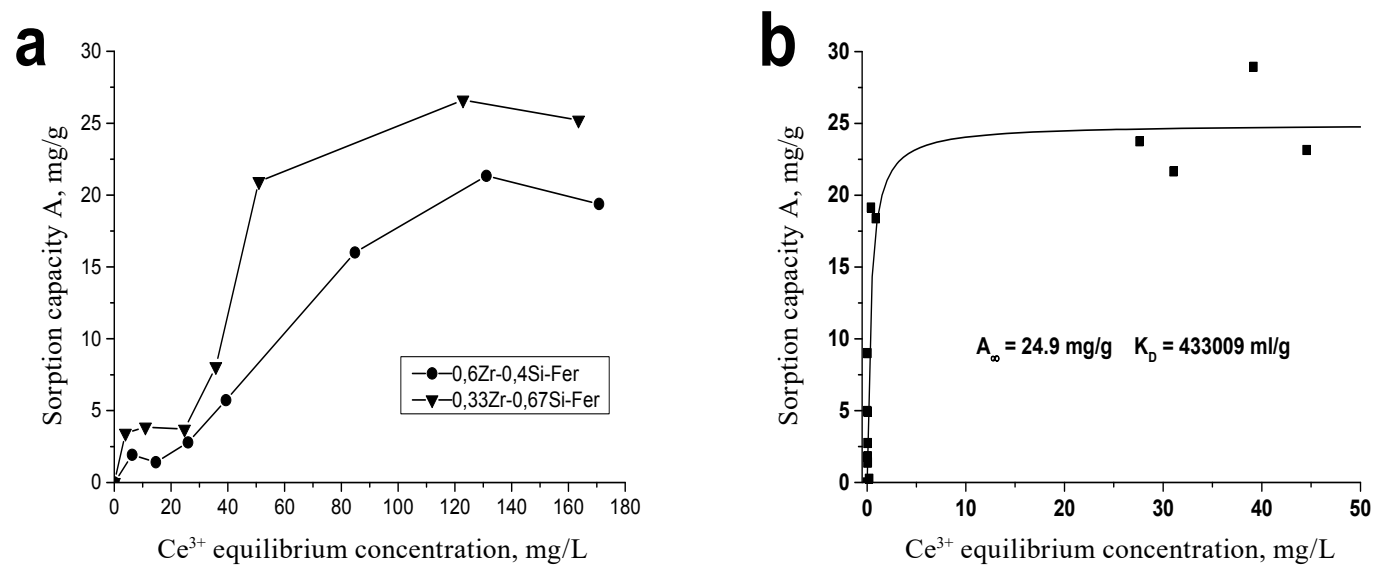

Рис. 3. Изотермы сорбции Се $\mathrm{Ce}^{3+}$ на магнитных композициях 0.6Zr-0.4Si-Fer и 0.33Zr-0.67Si-Fer при $20{ }^{\circ} \mathrm{C}(\mathrm{a})$; $\mathrm{R}_{2} \mathrm{POONa} / 0.5 \mathrm{Zr}-0.5 \mathrm{Si}-\mathrm{Fer}$ при $20^{\circ} \mathrm{C}$ (b) (точки - экспериментальные данные, линия - модель Ленгмюра)

Fig. 3. $\mathrm{Ce}^{3+}$ sorption isotherms for magnetic composites $0.6 \mathrm{Zr}-0.4 \mathrm{Si}-\mathrm{Fer}$ and $0.33 \mathrm{Zr}-0.67 \mathrm{Si}-\mathrm{Fer}$ at $20^{\circ} \mathrm{C}$ (a); $\mathrm{R}_{2} \mathrm{POONa} / 0.5 \mathrm{Zr}-0.5 \mathrm{Si}-\mathrm{Fer}$ at $20^{\circ} \mathrm{C}$ (b) (points - experimental data; line - Langmuir fit) 
0.67Si-Fer в отношении Се $\mathrm{e}^{3+}$ обусловлена, скорее всего, более высоким содержанием в ее структуре сильных кислотных центров типа $\mathrm{SiOH}$ групп [22], осуществляющих связывание катионов металлов на основе обменного взаимодействия. Следует также отметить, что в области низких концентраций $\mathrm{Ce}^{3+}$ в растворе (1-5 мг/л), типичных для реальных жидких отходов, композиции характеризуются низкими параметрами сорбции (A $\leq 4$ мг/Г $\left.\mathrm{Ce}^{3+}, \mathrm{K}_{\mathrm{D}} \sim 10^{2}-10^{3} \mathrm{Mл} / \Gamma\right)$, не удовлетворяющими требованиям эффективного сорбционного процесса.

С целью улучшения сорбционных характеристик магнитных композиций на примере образца $0.5 \mathrm{Zr}-0.5 \mathrm{Si}-\mathrm{Fer}$ исследована возможность функционализации поверхности сорбента группами -POONa путем нанесения $\mathrm{Na}^{+}$-формы бис-(2,4,4-триметилпентил)-фосфиновой кислоты $\left(\mathrm{R}_{2} \mathrm{POONa}\right)$, используемой в жидкостной экстракции f-металлов [23]. На рис. 36 изображена изотерма сорбции $\mathrm{Ce}^{3+}$ на образце $\mathrm{R}_{2} \mathrm{POONa} / 0.5 \mathrm{Zr}-0.5 \mathrm{Si}-\mathrm{Fer}$.

Функционализация поверхности приводит к замене первичных сорбционных центров исходного продукта на сорбционные центры другой природы, в частности -POONa, что можно видеть по изменению характера изотермы сорбции в отношении $\mathrm{Ce}^{3+}$. Экспериментальные данные, полученные для модифицированного продукта, удовлетворительно описываются моделью Ленгмюра с коэффициентом корреляции 0,95 , а сорбционная емкость в области низких равновесных концентраций церия возрастает в среднем на порядок по сравнению с немодифицированным образцом. При этом наблюдается увеличение на 2-3 порядка коэффициента распределения, значение которого достигает $0,4 \cdot 10^{6}$ мл/г.

Для выбора условий высокотемпературной твердофазной кристаллизации $\mathrm{Ce}^{3+}$-форм композиций $0.5 \mathrm{Zr}-0.5 \mathrm{Si}$-Fer и $\mathrm{R}_{2} \mathrm{POONa} / 0.5 \mathrm{Zr}-0.5 \mathrm{Si}-\mathrm{Fer}$ (образцы $\mathrm{Ce}^{3+} / 0.5 \mathrm{Zr}-0.5 \mathrm{Si}-\mathrm{Fer}$ и $\mathrm{Ce}^{3+}$ / $\left.\mathrm{R}_{2} \mathrm{POONa} / 0.5 \mathrm{Zr}-0.5 \mathrm{Si}-\mathrm{Fer}\right)$ с получением целевых $\mathrm{Zr}$-содержащих фаз $\left(\mathrm{ZrSiO}_{4}, \mathrm{ZrO}_{2}\right)$ как потенциальных матриц-иммобилизаторов $\mathrm{Ce}^{3+}$ методом синхронного термического анализа были исследованы процессы твердофазного превращения исходной композиции $0.5 \mathrm{Zr}-0.5 \mathrm{Si}-\mathrm{Fer}$, образцов $\mathrm{Ce}^{3+} / 0.5 \mathrm{Zr}-0.5 \mathrm{Si}-\mathrm{Fer}$ и $\mathrm{Ce}^{3+} / \mathrm{R}_{2} \mathrm{POONa} / 0.5 \mathrm{Zr}-0.5 \mathrm{Si}-\mathrm{Fer}$ при степенях насыщения церием, близких к максимальной (1-3 мас. \%), в температурном интервале $40-1200{ }^{\circ} \mathrm{C}$. ДСК и ТГ-кривые процессов термического превращения представлены на рис. 4.

По данным термического анализа, во всем изученном температурном интервале для исходной композиции $0.5 \mathrm{Zr}-0.5 \mathrm{Si}$-Fer и ее $\mathrm{Ce}^{+}$-формы не наблюдалось значительного изменения массы: потеря массы $\Delta$ m составила 2,86 мас. \% для исходного образца и 2,32 мас. \% для образца, содержащего церий. Основное изменение массы происходит в температурном интервале $40-800{ }^{\circ} \mathrm{C}$, в котором наблюдаются термические эффекты, связанные с выделением воды $(m / z=18)$ и выгоранием с поверхности ферросфер углерода $(m / z=44)$. Для исходной композиции на кривой ДСК в температурном интервале $550-1200{ }^{\circ} \mathrm{C}$ зафиксированы три экзоэффекта, проходящие без изменения массы, с температурными максимумами 725 , 878 и $1109{ }^{\circ} \mathrm{C}$, что обусловлено фазовыми превращениями композиции. Для композиции 0.5Zr-0.5 Si-Fer, содержащей $\mathrm{Ce}^{3+}$, на кривой ДСК в этом же температурном интервале также наблюдается три экзоэффекта, при этом первый экзоэффект смещен в область низких температур $\left(\mathrm{T}_{1}=684{ }^{\circ} \mathrm{C}\right)$, а второй и третий - в область более высоких температур $\left(\mathrm{T}_{2}=883{ }^{\circ} \mathrm{C}\right.$; $\mathrm{T}_{3}=1120^{\circ} \mathrm{C}$ ), что может быть связано со встраиванием $\mathrm{Ce}^{3+}$ в структуру фаз, формирующихся в высокотемпературной области. В случае гибридной композиции с нанесенным фосфорорганическим соединением на кривой ДСК проявляются дополнительные экзотермические 

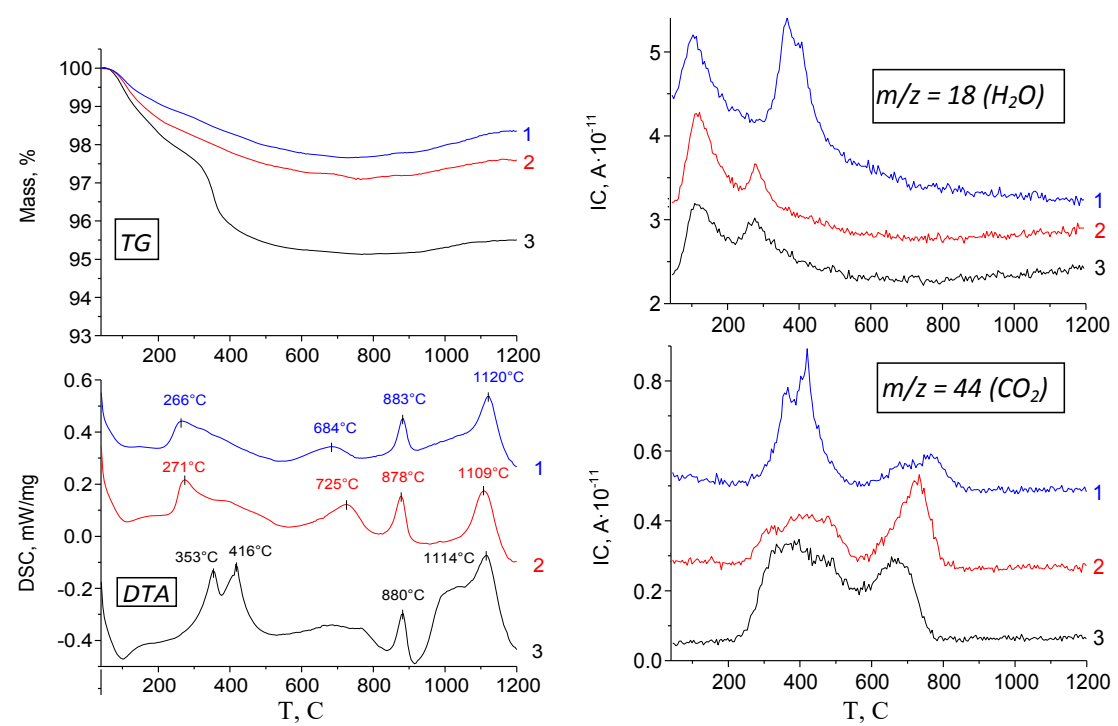

Рис. 4. Кривые ДСК и ТГ процессов термического превращения образцов $\mathrm{Ce}^{3+} / 0.5 \mathrm{Zr}-0.5 \mathrm{Si}-\mathrm{Fer}(1), 0.5 \mathrm{Zr}-$ $0.5 \mathrm{Si}-\mathrm{Fer}(2)$ и $\mathrm{Ce}^{3+} / \mathrm{R}_{2} \mathrm{POONa} / 0.5 \mathrm{Zr}-0.5 \mathrm{Si}-\mathrm{Fer}(3)$

Fig. 4. DSC and TG curves for thermal conversion of samples $\mathrm{Ce}^{3+} / 0.5 \mathrm{Zr}-0.5 \mathrm{Si}-\mathrm{Fer}(1), 0.5 \mathrm{Zr}-0.5 \mathrm{Si}-\mathrm{Fer}(2)$ and $\mathrm{Ce}^{3+} / \mathrm{R}_{2}$ POONa/0.5Zr-0.5Si-Fer (3)

эффекты в области $200-500{ }^{\circ} \mathrm{C}$ с максимумами 353 и $416{ }^{\circ} \mathrm{C}$, сопровождающиеся резким падением массы образцов. Вероятно, в этой области происходит разложение органической части нанесенного компонента с выделением воды и углекислого газа. ДСК-картина в области высоких температур характеризуется уширением экзотермического пика $\mathrm{T}_{1}$ в интервале 600-800 ${ }^{\circ} \mathrm{C}$ и наличием четких экзоэффектов с $\mathrm{T}_{2}=880{ }^{\circ} \mathrm{C}$ и $\mathrm{T}_{3}=1114{ }^{\circ} \mathrm{C}$. Отсутствие заметного смещения экзоэффекта при $\mathrm{T}_{3}$, наблюдаемого в случае $\mathrm{Ce}^{3+} / 0.5 \mathrm{Zr}-0.5 \mathrm{Si}-\mathrm{Fer}$, может свидетельствовать о том, что церий не ассоциируется с высокотемпературной фазой, возможно, циркона, a, скорее всего, взаимодействует с фосфатными группами на поверхности с образованием фосфата в температурной области до $500{ }^{\circ} \mathrm{C}$ с одновременным терморазложением органической составляющей.

На основании данных термического анализа для проведения твердофазной кристаллизации композиций была использована температура $1200{ }^{\circ} \mathrm{C}$. Качественный и количественный фазовые составы продуктов высокотемпературной обработки, а также параметры элементарной ячейки Zr-содержащих фаз, эталонных и экспериментально полученных, приведены в табл. 3.

Данные рентгенофазового анализа показывают, что в результате высокотемпературной обработки композиций на основе состава $\mathrm{Zr} /(\mathrm{Zr}+\mathrm{Si})=0,5$ формируется полифазная система, включающая фазы циркона с содержанием в кристаллической составляющей 26-52 мас. \% и тетрагонального $\mathrm{ZrO}_{2}$, содержание которого не превышает 2 мас. \%. О включении катиона $\mathrm{Ce}^{3+}$ в одну из $\mathrm{Zr}$-содержащих фаз с образованием твердых растворов может свидетельствовать изменение параметров кристаллической решетки циркона или $\mathrm{ZrO}_{2}$ относительно стехиометрических составов указанных соединений. Как видно из данных, приведенных в табл. 3, наиболее заметные изменения наблюдаются для параметра $c$ фазы $\mathrm{ZrO}_{2}$, а пара- 
Таблица 3. Фазовый состав продуктов твердофазной кристаллизации композиций $0.5 \mathrm{Zr}-0.5 \mathrm{Si}-\mathrm{Fer}$, $\mathrm{Ce}^{3+} / 0.5 \mathrm{Zr}-0.5 \mathrm{Si}-\mathrm{Fer}$ и $\mathrm{Ce}^{3+} / \mathrm{R}_{2} \mathrm{POONa} / 0.5 \mathrm{Zr}-0.5 \mathrm{Si}-\mathrm{Fer}$ при $1200{ }^{\circ} \mathrm{C}$

Table 3. Phase composition of products of solid-phase crystallization of composites $0.5 \mathrm{Zr}-0.5 \mathrm{Si}-\mathrm{Fer}, \mathrm{Ce}^{3+} / 0.5 \mathrm{Zr}-$ $0.5 \mathrm{Si}-\mathrm{Fer}$ and $\mathrm{Ce}^{3+} / \mathrm{R}_{2} \mathrm{POONa} / 0.5 \mathrm{Zr}-0.5 \mathrm{Si}-\mathrm{Fer}$ at $1200^{\circ} \mathrm{C}$

\begin{tabular}{|c|c|c|c|}
\hline \multirow{2}{*}{ Фаза } & \multicolumn{3}{|c|}{ Содержание фазы, мас. \% } \\
\hline & $0.5 \mathrm{Zr}-0.5 \mathrm{Si}-\mathrm{Fer}$ & $\mathrm{Ce}^{3+} / 0.5 \mathrm{Zr}-0.5 \mathrm{Si}-\mathrm{Fer}$ & $\mathrm{Ce}^{3+} / \mathrm{R}_{2} \mathrm{POONa} / 0.5 \mathrm{Zr}-0.5 \mathrm{Si}-\mathrm{Fer}$ \\
\hline Циркон, $\mathrm{ZrSiO}_{4}$ & 35 & 26 & 52 \\
\hline Гематит, $\mathrm{Fe}_{2} \mathrm{O}_{3}$ & 47 & 53 & 29 \\
\hline $\mathrm{ZrO}_{2}$ & 1,5 & 1,7 & 2 \\
\hline Кристобалит, $\mathrm{SiO}_{2}$ & 11 & 13 & 11 \\
\hline Кварц, $\mathrm{SiO}_{2}$ & 4 & 5 & 3 \\
\hline Муллит, $\mathrm{Al}_{6} \mathrm{Si}_{2} \mathrm{O}_{13}$ & 1 & 2 & 2 \\
\hline Стеклофаза & H.o.* & н.о. & H.о. \\
\hline \multicolumn{4}{|c|}{ Параметры кристаллической решетки Zr-содержащих фаз, А̊ } \\
\hline \multicolumn{4}{|c|}{ Циркон, $\mathrm{ZrSiO}_{4}$ (тетраг. синг., пр. гр. I4 $/$ amd, $\left.a=6,604 ; c=5,979\right)$} \\
\hline $\mathrm{a}$ & $6,6013(3)$ & $6,6018(5)$ & $6,6033(2)$ \\
\hline $\mathrm{c}$ & $5,9792(3)$ & $5,9797(3)$ & $5,9802(2)$ \\
\hline \multicolumn{4}{|c|}{$\mathrm{ZrO}_{2}$ (тетраг. синг., пр. гр. $\left.\mathrm{P}_{2} / \mathrm{nmc}, a=3,5984 ; c=5,152\right)$} \\
\hline a & $3,597(3)$ & $3,587(4)$ & $3,600(2)$ \\
\hline $\mathrm{c}$ & $5,198(7)$ & $5,225(11)$ & $5,200(5)$ \\
\hline
\end{tabular}

* не определяли.

метры решетки экспериментально полученной фазы циркона близки к эталонным. Однако при низком содержании церия в композициях (1-3 мас. \%) сделать однозначные выводы об изоморфном включении $\mathrm{Ce}^{3+}$ в структуру одной из $\mathrm{Zr}$-содержащих фаз не представляется возможным.

Магнитная композиция состава $0.5 \mathrm{Zr}-0.5 \mathrm{Si}-\mathrm{Fer}$ и ее гибридные формы с функционализированной поверхностью, полученные путем нанесения $\mathrm{Na}^{+}$соли бис-(2,4,4-триметилпентил)фосфиновой кислоты (образец $\mathrm{R}_{2} \mathrm{POONa} / 0.5 \mathrm{Zr}-0.5 \mathrm{Si}$-Fer) и $\gamma$-аминопропилтриэтоксисилана (образец $\left.\mathrm{RNH}_{2} / 0.5 \mathrm{Zr}-0.5 \mathrm{Si}-\mathrm{Fer}\right)$, были исследованы в процессе сорбционного извлечения катионов $\mathrm{Pb}^{2+}$. Определены изотермы сорбции $\mathrm{Pb}^{2+}$ из водных растворов в интервале концентраций $0,5-$ 100 мг/л $\mathrm{Pb}^{2+}$. Экспериментально полученные значения равновесной сорбции $\mathrm{Pb}^{2+}$ и их аппроксимация уравнением Ленгмюра представлены на рис. 5 , а значения параметров уравнения и коэффициентов распределения $\left(\mathrm{K}_{\mathrm{D}}\right)$ приведены в табл. 4.

Как следует из представленных данных, величина сорбционной емкости образцов варьирует в интервале 30-50 мг/г, при этом нанесение на поверхность композиции фосфатных групп позволяет повысить как величину сорбции $\mathrm{Pb}^{2+}$, так и коэффициент распределения относительно немодифицированного образца $0.5 \mathrm{Zr}-0.5 \mathrm{Si}$-Fer. К более значительному повышению ( в 4 раза) коэффициента распределения приводит аминирование поверхности.

Согласно данным РФА, термическая обработка $\mathrm{Pb}^{2+}$-формы композиции $0.5 \mathrm{Zr}-0.5 \mathrm{Si}-\mathrm{Fer}$ при $1060{ }^{\circ} \mathrm{C}$ также приводит к формированию полифазной системы, содержащей фазу циркона, которая способна концентрировать и надежно фиксировать катионы $\mathrm{Pb}^{2+}[4]$. 


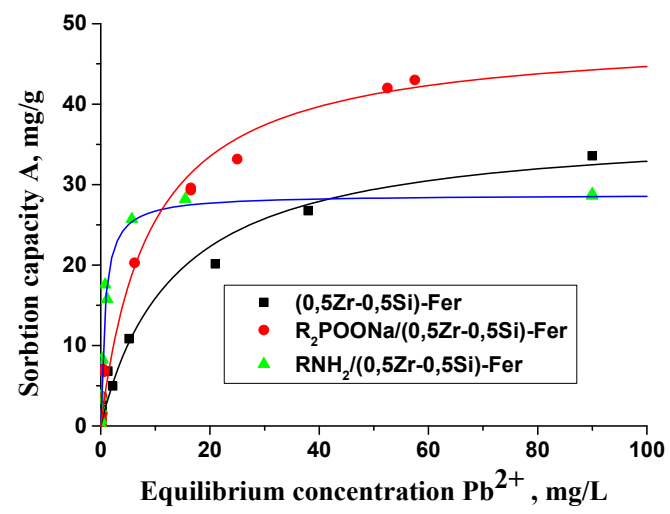

Рис. 5. Изотермы сорбции $\mathrm{Pb}^{2+}$ на магнитных композициях при $20^{\circ} \mathrm{C}$ (точки - экспериментальные данные, линии - модель Ленгмюра)

Fig. 5. $\mathrm{Pb}^{2+}$ sorption isotherms for magnetic compositions at $20^{\circ} \mathrm{C}$ (points - experimental data; lines - Langmuir fit)

Таблица 4. Параметры уравнения Ленгмюра и коэффициенты распределения для процесса сорбции $\mathrm{Pb}^{2+}$ магнитными композициями

Table 4. Parameters of Langmuir equation and distribution coefficients for $\mathrm{Pb}^{2+}$ sorption by magnetic compositions

\begin{tabular}{|c|l|c|c|c|}
\hline № & \multicolumn{1}{|c|}{ Образец } & $\begin{array}{c}\text { Коэффициент } \\
\text { корреляции (R) }\end{array}$ & $\begin{array}{c}\mathrm{a}_{\mathrm{m}}, \\
\mathrm{мг} / \Gamma\end{array}$ & $\begin{array}{c}\mathrm{K}_{\mathrm{D}}, \\
\text { мл/г }\end{array}$ \\
\hline 1 & $0.5 \mathrm{Zr}-0.5 \mathrm{Si}-\mathrm{Fer}$ & 0,99 & 37 & $0,4 \cdot 10^{4}$ \\
2 & $\mathrm{RNH}_{2} / 0.5 \mathrm{Zr}-0.5 \mathrm{Si}-\mathrm{Fer}$ & 0,99 & 29 & $1,5 \cdot 10^{4}$ \\
3 & $\mathrm{R}_{2} \mathrm{POONa} / 0.5 \mathrm{Zr}-0.5 \mathrm{Si}-\mathrm{Fer}$ & 0,99 & 49 & $0,9 \cdot 10^{4}$ \\
\hline
\end{tabular}

\section{Выводы}

Таким образом, впервые получены магнитные сорбенты катионов $\mathrm{Ce}^{3+}$ и $\mathrm{Pb}^{2+}$ на основе композиций ферросфер с мезо-/микропористым цирконосиликагелем разного состава в интервале отношений $\mathrm{Zr} /(\mathrm{Zr}+\mathrm{Si})$ 0,33-0,6. Установлено, что оптимальным составом для получения гранулированной формы сорбента является $\mathrm{Zr} /(\mathrm{Zr}+\mathrm{Si})=0,5$. Предложен способ повышения сорбционной емкости магнитных композиций и коэффициента распределения $\left(\mathrm{K}_{\mathrm{D}} \sim 10^{4}-10^{6}\right.$ мл/г) путем функционализации поверхности композиций группами $-\mathrm{NH}_{2}$ и -POONa. Показано, что твердофазная кристаллизация $\mathrm{Pb}^{2+}-$ и $\mathrm{Ce}^{3+}$-форм композиций на основе состава 0.5Zr-0.5Si-Fer при 1060 и $1200{ }^{\circ} \mathrm{C}$ соответственно приводит к формированию фазы циркона, обладающей потенциалом в качестве минералоподобной матрицы для иммобилизации $\mathrm{Ce}^{3+}$ и $\mathrm{Pb}^{2+}$.

Авторы выражают благодарность сотрудникам ИХХТ СО РАН О.А. Левицкой и В.Р. Кузик за выполнение анализа ИСП-МС. Работа выполнена за счет средств Федерального бюджета на реализацию проекта № V.45.3.3 в рамках программы ФНИ ГАН на 2013202022. 


\section{Список литературы}

1. Ломаев В.Г., Сердюк С.С. Чуктуконское месторождение ниобий-редкоземельных руд приоритетный объект для модернизации редкометалльной промышленности России. Журнал Сибирского федерального университета. Техника и технологии 2011. Т.4(2), С. 132-154. [Lomayev V.G., Serdyuk S.S. Chuktukon deposit of the niobium-rare earth ores is the top priority asset for modernization of the rare metal industry of Russia. Journal of Siberian Federal University. Engineering \& Technologies 2011.Vol. 4(2), P.132-154 (In Russ.)]

2. Металлургия благородных металлов. Под ред. Л.В. Чугаева. М.: Металлургия, 1978. 426 с. [Metallurgy of noble metals.Under Ed. L.V. Chugaev. Moscow: Metallurgy, 1978.426 p. (In Russ.)]

3. Waste forms technology and performance: Final report.Committee on Waste Forms Technology and Performance; Nuclear and Radiation Studies Board Division of Earth and Life Studies; National Research Council of the National Academies. Washington D.C.: The National Academies Press, 2011. 308 p.

4. Donald I.W. Waste immobilization inglass and ceramic based hosts: radioactive, toxic and hazardous wastes. Wiley-Blackwell, 2010.507 p.

5. Burakov B.E., Ojovan M.I., Lee W.E. Crystalline materials for actinide immobilization. London: Imperial College Press, 2010.197 p.

6. Hirose Y., Fukasawa T., Agraval D.K., Scheetz B.E., Nageswaran R., Curtis J.A., Limaye S.Y. An alternative process to immobilize intermediate wastes from LWR fuel reprocessing. Proc. Int. Conf. Waste Management (WM'99), February 28 - March 4, 1999. Tucson, Arizona, USA.

7. Meldrum A.A., BoatnerL.A., Ewing R.C. Comparison of radiation effects in crystalline $\mathrm{ABO}_{4}$ type phosphates and silicates. Mineralogical Magazine 2000. Vol. 64, P. 185-194.

8. Pichot E., Dacheux N., Brandel V., Genet M.Investigation of ${ }^{137} \mathrm{Cs}^{+},{ }^{85} \mathrm{Sr}^{2+}$ and ${ }^{241} \mathrm{Am}^{3+}$ ion exchange on thorium phosphate hydrogen phosphate and their immobilization in the thorium phosphate diphosphate. New J. Chem. 2000. Vol.24, P. 1017-1023.

9. Vereshchagina T.A., Fomenko E.V., Vasilieva N.G., Solovyov L.A., Vereshchagin S.N., Bazarova Zh.G., Anshits A.G. A novel layered zirconium molybdate as a precursor to a ceramic zirconomolybdate host for lanthanide bearing radioactive waste. Journal of Materials Chemistry 2011. Vol.21, P. 2001-2007.

10. Amphlett C. B. Inorganic Ion exchengers. Elsevier Pub. Co: New York, London, 1964.141 p.

11. Sepehrian H., Yavari R., Waqif-Husain S., Ghannadi-Maragheh M. Separation of radionuclides on mesoporous zirconium silicate:a novel sorbent.Separation Science and Technology 2008. Vol. 43, P. 3269-3285.

12. Кизильштейн Л.Я., Дубов И.В., Шпицглуз А.Л., Парада С.Г. Компоненты зол и шлаков ТЭС. Москва: Энергоатомиздат, 1995.176 с. [Kizilshteyn L.Ya., Dubov I.V., Shpitsgluz A.L., Parada S.G. Components of ashes and slag TPP.Moscow: Energoatomizdat, 1995. 176 p.(In Russ.)]

13. Vassilev S.V., Menendez R., Alvarez D., Diaz-Somoano M., Martinez-Tarazona M.R. Phasemineral and chemical composition of coal fly ashes as a basis for their multicomponent utilization. 1 . Characterization of feed coals and fly ashes. Fuel 2003.Vol.82, P.1793-1811.

14. Sharonova O.M., Anshits N.N., Solovyov L.A., Salanov A.N., Anshits A.G. Relationship between composition and structure of globules in narrow fractions of ferrospheres. Fuel 2013.Vol. 111, P. 332-343. 
15. Vereshchagina T.A., Fedorchak M.A., Sharonova O.M., Fomenko E.V., Shishkina N.N., Zhizhaev A.M., Kudryavtsev A.N., Frank L.A., Anshits A.G. Ni ${ }^{2+}$-zeolite/ferrosphere and $\mathrm{Ni}^{2+}$-silica/ ferrosphere beads for magnetic affinity separation of histidine-tagged proteins. Dalton Transactions 2016. V. 45, P. 1582-1592.

16. Breck D.W., Zeolite Molecular Sieves: Structure, Chemistry, and Use. New York: John Wiley \&Sons, 1974. 771p.

17. Vereshchagina T.A., Vereshchagin S.N., Shishkina N.N., Solovyov L.A., Vasilieva N.G., Anshits A.G. Microsphere zeolite materials derived from coal fly ash cenospheres as precursors to mineral-like aluminosilicate hosts for ${ }^{135,137} \mathrm{Cs}$ and ${ }^{90} \mathrm{Sr}$. Journal of Nuclear Materials. 2013. V. 437, P. $11-18$.

18. Anshits N.N., Salanov A.N., Vereshchagina T.A., Kruchek D.M., Bajukov O.A., Tretyakov A.A., Revenko Yu.A., Anshits A.G. Composition, morphology, properties of coal fly ash microspheres and their application for conditioning liquid radioactive waste. International Journal of Nuclear Energy Science and Technology 2006. Vol. 2.(1\2), P.8-24.

19. Vereshchagina T.A., Anshits N.N., Sharonova O.M., Vasilieva N.G., Vereshchagin S.N., Shishkina N.N., Fomenko E.V., Anshits A.G. Polyfunctional microspherical materials for long-term burial of liquid radioactive wastes. Glass Physics and Chemistry 2008. Vol.34(5), P. 547-558.

20. Bayukov O.A., Anshits N.N., Petrov M.I., Balaev A.D., Anshits A.G. Composition of ferrospinel phase and magnetic properties of microspheres and cenospheres from fly ashes. Materials Chemistry and Physics 2009. Vol.114(1), P. 495-503.

21. Drozhzhin V.S., Danilin L.D., Pikulin I.V., Khovrin A.N., Maximova N.V., Regiushev S.A., Pimenov V.G. Functional materials on the basis of cenospheres, 2005 World of Coal Fly Ash (WOCA). April 11-15, 2005. Lexington, Kentucky, USA. 9 p. URL:http://www.flyash.info/2005/47dro.pdf (дата актуализации 31.01.2019)

22. Viter V.N. Sol-gel synthesis of mesoporous mixed porous oxides $\mathrm{ZrO}_{2}-\mathrm{SiO}_{2}$. Russian Journal of Applied Chemistry 2010. Vol.83(2), P.195-199.

23. Мастрюкова Т.А., Артюшин О.И., Одинец И.Л., Тананаев И.Г. Экстракционные свойства нейтральных фосфорорганических соединений для фракционирования радиоактивных отходов. Российский химический журнал 2005. Т. 49(2), С. 86-96 [Mastryukova T.A., Artyushin O.I., Odinets I.L., Tananaev I.G. Extraction properties of neutral organophosphorus compounds for radioactive waste fractionation. Rossiyskiy Khimicheskiy Zhurnal 2005. T. 49(2), P. 86-96 (In Russ.)]

24. Ворошилов О.И., Киселев А.В., Никитин Ю.С. Синтез и исследование кремнезёмных носителей с поверхностью, модифицированной $\gamma$-аминопропильными группами. Коллоидный журнал 1980. T. 42(2), C. 223-229 [Voroshilov O.I., Kiselev A.V., NikitinYu.S. Synthesis and study of silica carriers with a surface modified with $\gamma$-aminopropyl groups. Colloidniy Zhurnal 1980. Vol. 42(2), P. 223-229 (In Russ.)]

25. Reitveld H. A profile refinement method for nuclear and magnetic structures. Journal of Applied Crystallography 1969. Vol. 2, P. 65-71.

26. Solovyov L.A. Full-profile refinement by derivative difference minimization. Journal of Applied Crystallography 2004.Vol. 3, P. 743-749. 